\title{
BMJ Open Low length/weight growth trajectories of early-term infants during the first year: evidence from a longitudinal study in China
}

\author{
Kai Chen (D) , ${ }^{1,2}$ Lulu Song, ${ }^{2}$ Bingqing Liu, ${ }^{2}$ Mingyang Wu, ${ }^{2}$ Yunyun Liu, ${ }^{2}$ \\ Lulin Wang, ${ }^{2}$ Jianing $\mathrm{Bi}^{2}{ }^{2}$ Qing Liu, ${ }^{2}$ Yiming Zhang, ${ }^{1}$ Zezhong Tang, ${ }^{3}$ \\ Youjie Wang (D), ${ }^{2}$ Rong Yang ${ }^{1}$
}

To cite: Chen K, Song L, Liu B, et al. Low length/weight growth trajectories of early-term infants during the first year: evidence from a longitudinal study in China. BMJ Open 2022;12:e051436. doi:10.1136/ bmjopen-2021-051436

- Prepublication history and additional supplemental material for this paper are available online. To view these files, please visit the journal online (http://dx.doi.org/10.1136/ bmjopen-2021-051436).

Received 18 March 2021 Accepted 24 September 2021

\section{Check for updates}

(c) Author(s) (or their employer(s)) 2022. Re-use permitted under CC BY-NC. No commercial re-use. See rights and permissions. Published by BMJ.

${ }^{1}$ Wuhan Children's Hospital (Wuhan Maternal and Child Healthcare Hospital), Tongji Medical College, Huazhong University of Science \& Technology, Wuhan, Hubei, People's Republic of China ${ }^{2}$ Department of Maternal and Child Health, School of Public Health, Tongji Medical College, Huazhong University of Science and Technology, Wuhan, Hubei, People's Republic of China ${ }^{3}$ Department of Pediatrics, Peking University First Hospital, Beijing, China

Correspondence to

Dr Rong Yang:

442748767@qq.com

\section{ABSTRACT}

Objective To identify common length, weight and body mass index (BMI) growth trajectories of term infants during infancy, and to determine their association with early-term infants.

Design Prospective longitudinal study.

Setting Wuhan, China.

Patients A total of 4308 term infants (born at 37-41 weeks of gestation) were included. All term infants were single live birth with no defects and birth weight $\geq 2500 \mathrm{~g}$, and their mothers were permanent residents of Wuhan for more than 2 years. After excluding 887 infants, a total of 3421 term infants (1028 early-term infants born at 37-38 weeks of gestation and 2393 full-term infants born at 39-41 weeks of gestation) entered the statistical analysis stage.

Main outcome measures Patterns of length, weight and BMI growth trajectories by using group-based trajectory modelling.

Results Three distinct physical growth trajectories were identified as follows: length: low stable (1056, 30.9\%), moderate stable $(1887,55.2 \%)$ and high increasing (477, $13.9 \%)$; weight: low stable (1031, $30.1 \%)$, moderate stable (1884, 55.1\%) and high increasing (505, 14.8\%); BMl: low stable $(689,20.1 \%)$, moderate stable $(2167,63.4 \%)$ and high increasing $(564,16.5 \%)$. Compared with the full-term infants, early-term infants were more likely to remain at low-stable trajectory in length (OR: $1.40 ; 95 \% \mathrm{Cl}: 1.19$ to 1.66$)$ and weight (OR:1.29; $95 \% \mathrm{Cl}: 1.09$ to 1.53 ). These associations were still statistically significant after adjusting potential confounders and were more evident among girls in the stratified analysis. There was no statistical association between BMI trajectory patterns and gestational age categories.

Conclusion Our results suggested the heterogeneity of term infants existed in length, weight and BMl growth trajectories of early childhood. Compared with full-term birth, early-term birth was related to low length and weight trajectories rather than BMI trajectory. Further research is needed to evaluate the duration of these low trajectories and their possible long-term health effects.

\section{INTRODUCTION}

Early-term infants (born at 37-38 weeks of gestation $)^{1}$ have been considered to be a heterogeneous group compared with
Strengths and limitations of this study

- This was the first study conducted in China to reveal the physical growth trajectories of term infants during their first year.

- In this study, group-based trajectory modelling was used to hypothesise the heterogeneity between subgroups, which was ignored in some previous studies.

- Unlike the most previous studies, this study observed the differences in physical growth between early-term and full-term infants from two dimensions (multiple cross-sectional time points and the longitudinal growth trajectory), which could be more helpful.

- Our major limitation was the lack of the longer-term follow-up, which would be important for exploring the duration of different growth trajectory patterns and their health effects.

full-term infants (born at 39-41 weeks of gestation). More and more evidence has suggested that early-term infants are more likely to have a host of adverse health outcomes compared with full-term infants. ${ }^{2}$ Early-term births, compared with full-term births, are not only associated with the increased risk of neonatal mortality, morbidity and admissions, ${ }^{3-7}$ but also associated with the long-term adverse outcomes, such as developmental delay, ${ }^{8}$ wheezing and asthma in childhood, ${ }^{9}{ }^{10}$ cognitive deficit, ${ }^{11}$ poor school performance ${ }^{1213}$ and psychiatric problem. ${ }^{14}{ }^{15}$ The high number of early-term births creates a health burden and has long been considered a public health problem. ${ }^{16-18}$

Few studies have explored the physical growth of early-term infants. Evidence from the UK Millennium Cohort Study suggested that height at 3 years was negatively associated with gestational age. However, the association 
was no longer statistically significant among the early-term infants after adjusting the child's age at interview and potential confounders. ${ }^{17}$ It is necessary to clarify how long the gestational age affects children's height (also known as the length in infancy) and weight. A cohort study of small-for-gestational age (SGA) children conducted in Japan showed that childhood poor height trajectory was related to early-term infants. ${ }^{19}$ However, height or weight growth may be heterogeneous during early childhood and these two above-mentioned studies assumed homogeneity of the study population. It is necessary to conduct a research on early-term infants that aims to identify physical growth trajectories with an analytical approach that can recognise the heterogeneity of the study population.

Group-based trajectory modelling (GBTM) is one of the latent mixture modelling, in which trajectory groups are used as a statistical device for approximating possible trajectories across population members. ${ }^{20}$ GBTM assumes heterogeneity between subgroups and matches each individual to the appropriate subgroup trajectory. Several studies have used the GBTM to identify distinct body mass index (BMI) trajectories. A study of (mostly) Caucasian population in the USA identified four distinct BMI trajectory patterns (consistently low, increase in the first year, increase in the second year and consistently high) among children younger than 2 years old. ${ }^{21}$ An Australia birth cohort study identified four distinct BMI trajectory patterns (low, intermediate, high or accelerating growth) from birth to 3.5 years old, and found that maternal obesity in early pregnancy increased the risk of being in the accelerating trajectory patterns. ${ }^{22}$ However, there is a lack of study on the impact of early-term birth on physical growth trajectories.

The purposes of our study were to identify distinct length, weight and BMI growth trajectories of term infants during the first year of life (the fastest physical growth period after birth) by using GBTM, and to explore the association between early-term birth and physical growth trajectories in China.

\section{METHODS}

\section{Study population}

This study contains a total of 4308 term infants selected from a previous case-control study. The cases were every pregnant woman who had a preterm birth between 10 June 2011 and 9 June 2013, and controls (matching with cases on the place of residence) were randomly selected from all women with term births (37 weeks of gestation and beyond). All term infants were a single live birth with no birth defects and birth weight $\geq 2500 \mathrm{~g}$ and their mothers had lived in the inner-city districts of Wuhan for more than 2 years and gave birth here. More details can be found in the previous study. ${ }^{23}$ In this study, we continued to investigate the physical growth of these 4308 term infants. Briefly, their mothers were required to complete the face-to-face interview using a structured questionnaire including characteristics of parents and infants. The data of this study contain six measurements of the length and weight within the first year of life (months $0,1,3,6,8$ and 12). The first measurement was taken at birth in the delivery hospital, while the rest five measurements were taken by trained doctors in the community health service centres using standard techniques. The questionnaire information and anthropometric data were uploaded and stored in a uniform database.

In the statistical analysis stage, we excluded 887 infants because of post-term birth (42 weeks of gestation and beyond), SGA, logically incorrect (for example, the length of 8 months is lower than the length of 6 months), biologically implausible (length-for-age z-score (LAZ) $<-6$ or $>6$, weight-for-age z-score (WAZ) $<-6$ or $>5$ ) anthropometric data and $<2$ visits. Finally, 3421 term infants were eligible and included in the analysis.

\section{Gestational age and growth trajectory}

Gestational age at birth was calculated based on the last menstrual period (LMP) and/or ultrasound scans. The results of ultrasound scans offered to all pregnant women would be adopted when they could not provide the exact date of their LMP. We divided infants into early-term (37-38 weeks of gestation) groups and full-term (39-41 weeks of gestation) groups.

Due to the large number of infants, it was difficult to ensure that all participants take anthropometric measurements at completely accurate follow-up time points. For example, an infant with an actual age (the date when the anthropometric measurements were taken minus the date of birth) of 96 days would be treated as 3 months old for management. As shown in online supplemental table S1, there was no significant difference between the actual age of early-term infants at every follow-up time point with that of full-term infants, which also improved the reliability of our results. The BMI was calculated as weight in kilograms divided by length in metres squared $\left(\mathrm{kg} / \mathrm{m}^{2}\right)$. According to the WHO Child Growths Standards at different ages, length, weight, and BMI were converted to LAZ, WAZ, and BMI-for-age z-score (BMIZ), respectively. The infants whose length was measured and analysed at these six time points were 3418 (99.9\%), 3245 (94.9\%), 3037 (88.8\%), 2899 (84.7\%), $2844(83.1 \%)$ and $2734(79.9 \%)$, respectively. The infants whose weight was measured and analysed at these six time points were 3417 (99.9\%), 3245 (94.9\%), 3037 (88.8\%), 2889 (84.4\%), $2800(81.8 \%)$ and $2679(78.3 \%)$, respectively. Then LAZ, WAZ and BMIZ were used to model physical growth trajectories by GBTM. Finally, the length, weight and BMI growth trajectories included 3420 out of 3421 infants, respectively.

\section{Covariates}

Information on parental height and weight (measured by skilled doctors or nurses), maternal weight before pregnancy, smoking and drinking in pregnancy was obtained from the questionnaire survey. Information on maternal age at delivery, parity, delivery mode, pregnancy 
complications, infant sex, birth length, birth weight and neonatal complications was abstracted from the medical records. In our study, gestational hypertension or preeclampsia, placental abruption or placenta previa and premature rupture of membranes were classified as pregnancy complications. Meanwhile, respiratory distress syndrome, neonatal pneumonia, pathological jaundice and neonatal diarrhoea were classified as neonatal complications. Maternal pre-pregnancy BMI $\left(\mathrm{kg} / \mathrm{m}^{2}\right)$ was calculated as maternal weight before pregnancy $(\mathrm{kg})$ divided by maternal height squared $\left(\mathrm{m}^{2}\right)$ and $\geq 24.0$ was considered maternal pre-pregnancy overweight/obesity. Maternal weight gain during pregnancy was obtained by subtracting maternal weight before pregnancy from the weight at delivery.

\section{Statistical analysis}

Physical growth trajectories were identified by GBTM conducted in SAS version 9.4 Proc Traj. ${ }^{24} 25$ According to professional interpretations and the Bayesian information criterion, the optimal model in the matter of the number of subgroups and the best polynomial order of each subgroup trajectory are selected. The posterior probability of each subgroup that we selected in this study was $\geq 0.70$. It meant all the subgroups fit well.

Analysis of covariance was used to compare differences in body growth at every follow-up. Polytomous logistic regression model was used to estimate the association of gestational age categories (early-term and full-term) and patterns of physical growth trajectories. Variables relating to childhood growth were included in the adjusted model, ${ }^{1026-28}$ such as maternal age at delivery, parental height, parental weight, smoking or drinking in pregnancy. Just like the method of screening covariates in some high-quality studies, ${ }^{29}{ }^{30}$ some variables that changed the matched OR more than $10 \%$ were included in our adjusted model, such as pregnancy and neonatal complications, parity, delivery mode and infant sex.

Categorical variables were presented by number (percentage) and compared by the $\mathrm{X}^{2}$ test. Continuous variables were presented by mean (SD) for normally distributed data or median (IQR) for skewed data, and compared by independent t-test or non-parametric test. All analyses were completed by using SAS software V.9.4 (SAS Institute, Inc., Cary, North Carolina). A significance level was set at 0.05 .

\section{Patient and public involvement}

No patients or the public were involved in the study design, setting the research questions, interpretation or writing up of results, or reporting of the research.

\section{RESULTS}

Among 3421 participants, there were 1028 (30.0\%) earlyterm infants and 2393 (70.0\%) full-term infants. Descriptive characteristics of infants stratified by gestational age categories were presented in table 1. Early-term infants were more likely to be boys, born by caesarean section and have neonatal complications, while their mothers were older and more likely to have complications during pregnancy. As for the comparison of growth status at the single time point (table 2), early-term infants were lower at months $0,1,3$ and 6 in length, and were lower at

\begin{tabular}{|c|c|c|c|c|}
\hline & Total $(n=3421)$ & Early-term $(n=1028)$ & Full-term ( $n=2393)$ & $P$ value \\
\hline \multicolumn{5}{|l|}{ Maternal and paternal characteristics } \\
\hline Maternal height, mean (SD), cm & $161.3(4.4)$ & $161.1(4.5)$ & $161.4(4.4)$ & 0.057 \\
\hline Maternal weight before pregnancy, mean (SD), kg & $53.5(6.6)$ & $53.8(6.6)$ & $53.4(6.7)$ & 0.146 \\
\hline Paternal height, mean (SD), cm & $173.5(4.7)$ & $173.6(4.8)$ & $173.4(4.6)$ & 0.368 \\
\hline Paternal weight, mean (SD), kg & $71.0(9.7)$ & $71.1(10.1)$ & $70.9(9.6)$ & 0.521 \\
\hline Smoking in pregnancy, no (\%) & $22(0.6)$ & $9(0.9)$ & $13(0.5)$ & 0.265 \\
\hline \multicolumn{5}{|l|}{ Infant characteristics } \\
\hline Boys, no (\%) & $1866(54.5)$ & $612(59.5)$ & $1254(52.4)$ & $<0.001$ \\
\hline Firstborn, no (\%) & $2876(84.1)$ & $824(80.2)$ & $2052(85.8)$ & 0.001 \\
\hline Birth length, mean (SD), cm & $50.2(1.2)$ & $49.9(1.3)$ & $50.3(1.1)$ & $<0.001$ \\
\hline Birth weight, mean (SD), kg & $3.38(0.37)$ & $3.25(0.38)$ & $3.44(0.35)$ & $<0.001$ \\
\hline Neonatal complications, no (\%) & $351(10.3)$ & $122(11.9)$ & $229(9.6)$ & 0.042 \\
\hline
\end{tabular}


Table 2 Mean length, weight, and BMI of term infants and mean length, weight, and BMI differences compared with earlyterm infants

\begin{tabular}{|c|c|c|c|c|}
\hline & $\begin{array}{l}\text { Early-term infants, mean } \\
(95 \% \mathrm{Cl})\end{array}$ & $\begin{array}{l}\text { Full-term infants, mean } \\
(95 \% \mathrm{Cl})\end{array}$ & $\begin{array}{l}\text { Unadjusted differences } \\
(95 \% \mathrm{Cl})\end{array}$ & $\begin{array}{l}\text { Adjusted differences } \\
(95 \% \mathrm{Cl})\end{array}$ \\
\hline \multicolumn{5}{|l|}{ Length, $\mathrm{cm}$} \\
\hline Month 0 & 49.9 (49.8 to 50.0$)$ & 50.3 (50.3 to 50.4$)$ & $-0.4(-0.5$ to -0.4$)$ & $-0.4(-0.5$ to -0.4$)$ \\
\hline Month 1 & 54.4 (54.2 to 54.5$)$ & 54.9 (54.8 to 55.0$)$ & $-0.5(-0.7$ to -0.4$)$ & $-0.5(-0.7$ to -0.4$)$ \\
\hline Month 3 & 61.5 (61.4 to 61.7$)$ & 61.9 (61.8 to 62.0$)$ & $-0.4(-0.5$ to -0.2$)$ & $-0.3(-0.5$ to -0.2$)$ \\
\hline Month 6 & 67.9 (67.8 to 68.1$)$ & 68.1 (68.0 to 68.2 ) & $-0.2(-0.3$ to 0.0$)$ & $-0.2(-0.3$ to 0.0$)$ \\
\hline Month 8 & 71.6 (71.4 to 71.7$)$ & 71.6 (71.5 to 71.7$)$ & $-0.1(-0.2$ to 0.2$)$ & $-0.1(-0.3$ to 0.1$)$ \\
\hline Month 12 & 76.5 (76.3 to 76.7$)$ & 76.5 (76.4 to 76.6$)$ & 0.0 (-0.0 to 0.2$)$ & $0.0(-0.2$ to 0.2$)$ \\
\hline \multicolumn{5}{|l|}{ Weight, kg } \\
\hline Month 0 & 3.25 (3.23 to 3.28$)$ & 3.44 (3.42 to 3.45$)$ & $-0.18(-0.21$ to -0.16$)$ & $-0.18(-0.21$ to -0.16$)$ \\
\hline Month 1 & 4.67 (4.64 to 4.71$)$ & 4.78 (4.76 to 4.80$)$ & $-0.11(-0.15$ to -0.07$)$ & $-0.11(-0.15$ to -0.07$)$ \\
\hline Month 3 & 6.78 (6.73 to 6.83$)$ & 6.82 (6.78 to 6.85$)$ & $-0.04(-0.10$ to 0.02$)$ & $-0.03(-0.09$ to 0.04$)$ \\
\hline Month 6 & 8.53 (8.47 to 8.59$)$ & 8.50 (8.46 to 8.53$)$ & $0.04(-0.04$ to 0.10$)$ & $0.04(-0.04$ to 0.11$)$ \\
\hline Month 8 & 9.40 (9.34 to 9.46$)$ & 9.30 (9.26 to 9.35$)$ & $0.04(-0.02$ to 0.17$)$ & 0.04 (0.01 to 0.18$)$ \\
\hline Month 12 & 10.45 (10.38 to 10.52$)$ & 10.39 (10.35 to 10.44$)$ & $0.06(-0.02$ to 0.14$)$ & $0.06(-0.03$ to 0.15$)$ \\
\hline \multicolumn{5}{|l|}{$\mathrm{BMI}, \mathrm{kg} / \mathrm{m}^{2}$} \\
\hline Month 0 & 13.05 (12.98 to 13.12$)$ & 13.56 (13.51 to 13.60$)$ & $-0.50(-0.58 \text { to } 0.43)^{\star}$ & $-0.50(-0.58 \text { to } 0.43)^{\star}$ \\
\hline Month 1 & 15.78 (15.69 to 15.88$)$ & 15.85 (15.79 to 15.90$)$ & $-0.06(-0.17$ to 0.04$)$ & NAt \\
\hline Month 3 & 17.88 (17.77 to 17.98$)$ & 17.76 (17.70 to 17.83$)$ & 0.12 (-0.01 to 0.24$)$ & NA† \\
\hline Month 6 & 18.46 (18.36 to 18.56$)$ & 18.30 (18.23 to 18.37$)$ & $0.16(0.03 \text { to } 0.28)^{*}$ & $0.16(0.02 \text { to } 0.29)^{\star}$ \\
\hline Month 8 & 18.36 (18.26 to 18.45$)$ & 18.16 (18.09 to 18.22$)$ & $0.20(0.08 \text { to } 0.32)^{\star}$ & $0.20(0.07 \text { to } 0.33)^{*}$ \\
\hline Month 12 & 17.85 (17.75 to 17.94$)$ & 17.73 (17.67 to 17.79$)$ & $0.12(0.01 \text { to } 0.23)^{\star}$ & $0.11(-0.01$ to 0.24$)$ \\
\hline
\end{tabular}

Means and mean differences are weighted with participants and cases lost to follow-up weights.

Adjusted for infant's correct age at visit.

${ }^{*} \mathrm{P}<0.05$.

†Not applicable to ANCOVA

ANCOVA, analysis of covariance; BMI, body mass index.

months 0 and 1 in weight than full-term infants. Different from the length and weight, early-term infants' BMI status were lower at birth but higher at months 6 and 8 .

Three distinct length trajectories from birth to 1 year old were identified among 3420 term infants by GBTM. Model fit results when the LAZ, WAZ and BMIZ trajectories were in the best fit according to GBTM were shown in the online supplemental table S2. The fitted value of the trajectory at each follow-up time point was shown in the online supplemental table S3. As shown in figure 1, LAZ in 1056 infants $(30.9 \%)$ decreased slightly at 1 month old and remained at a low level (lowstable subgroup); LAZ in $1887(55.2 \%)$ infants maintained moderate levels throughout the follow-up period (moderate-stable subgroup); and LAZ in 477 (13.9\%) infants started with relatively high level, increased rapidly before 8 months old and slightly decreased at 12 months old (high-increasing subgroup). The proportion of earlyterm infants in the three subgroups (low stable, moderate stable and high increasing) was $37.4 \%, 52.0 \%$ and $10.6 \%$, respectively, while the proportion of full-term infants was $28.1 \%, 56.5 \%$ and $15.4 \%$, respectively. The distributions of LAZ trajectory patterns were statistically different $(p<0.001)$ between early-term infants and full-term infants. Three distinct weight and BMI trajectories (also characterised as low-stable, moderate-stable and highincreasing subgroups) were displayed in figures 2 and 3, respectively. The distributions of WAZ trajectory patterns were also statistically different $(\mathrm{p}=0.001)$ between earlyterm infants $(34.6 \%, 52.0 \%$ and $13.4 \%$, respectively) and full-term infants $(28.2 \%, 56.4 \%$ and $15.4 \%$, respectively). Different from LAZ and WAZ trajectories, the distributions of BMIZ trajectory patterns were not statistically different $(\mathrm{p}=0.779)$ between early-term infants $(20.8 \%$, $62.5 \%$ and $16.6 \%$, respectively) and full-term infants $(19.9 \%, 63.7 \%$ and $16.4 \%$, respectively).

Table 3 showed the results of polytomous logistic regression analyses. Early-term infants had greater odds of being in low-stable growth patterns both in length (OR: 1.45; 95\% CI: 1.23 to 1.70 ) and weight (OR: 1.33 ; 95\% CI: 1.13 to 1.57). Early-term birth infants had fewer odds of being in the high-increasing growth pattern only in length (OR: 


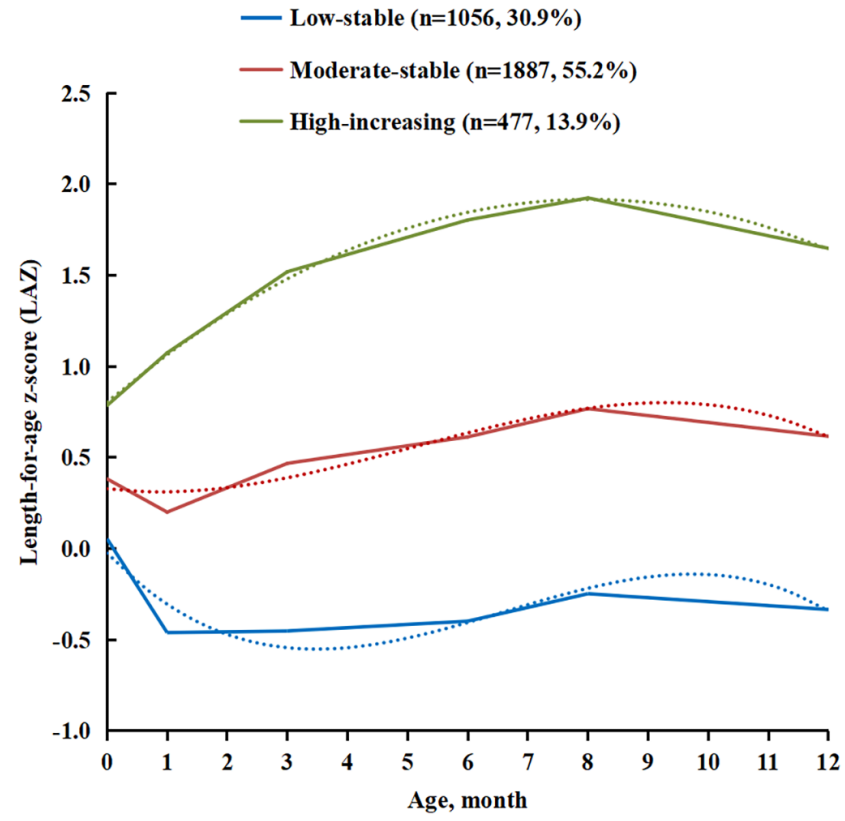

Figure 1 Trajectories in length-for-age z-score among 3420 infants (solid line for measuring and dotted line for modelling).

$0.75 ; 95 \% \mathrm{CI}, 0.60$ to 0.95$)$. The associations were slightly decreased but still significant after adjusting potential confounding factors. There was no statistical association between BMI trajectory patterns and gestational age categories. Results of association stratified by infant sex were presented in table 4 . These mentioned associations were more evident among girls, but the association between high-increasing growth pattern and early-term birth among boys was no longer statistically significant.

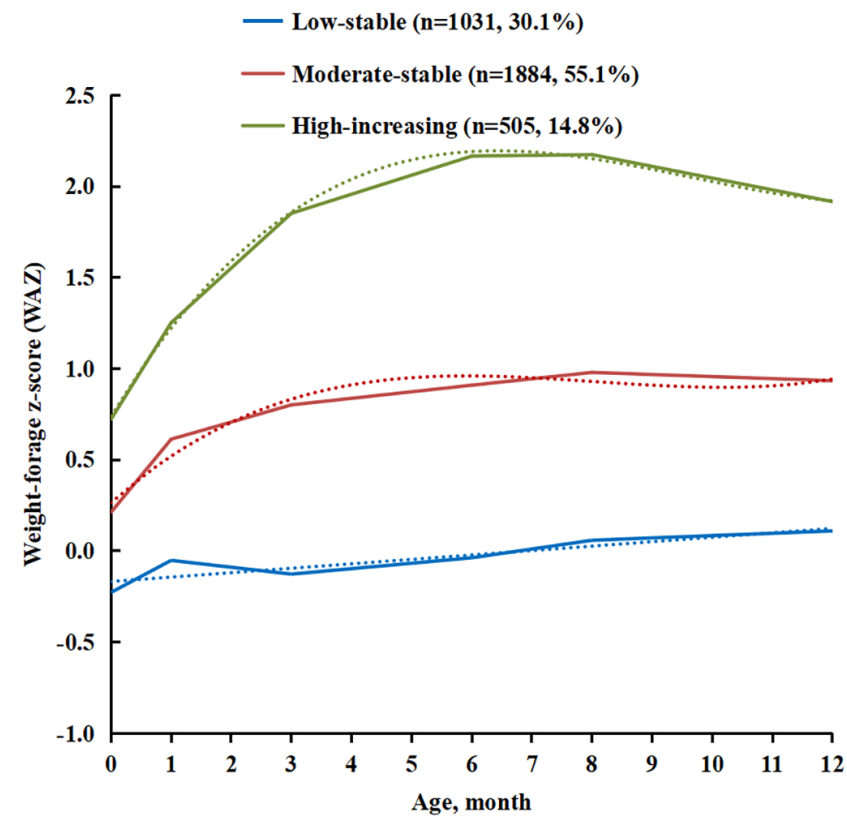

Figure 2 Trajectories in weight-for-age z-score among 3420 infants (solid line for measuring and dotted line for modelling).

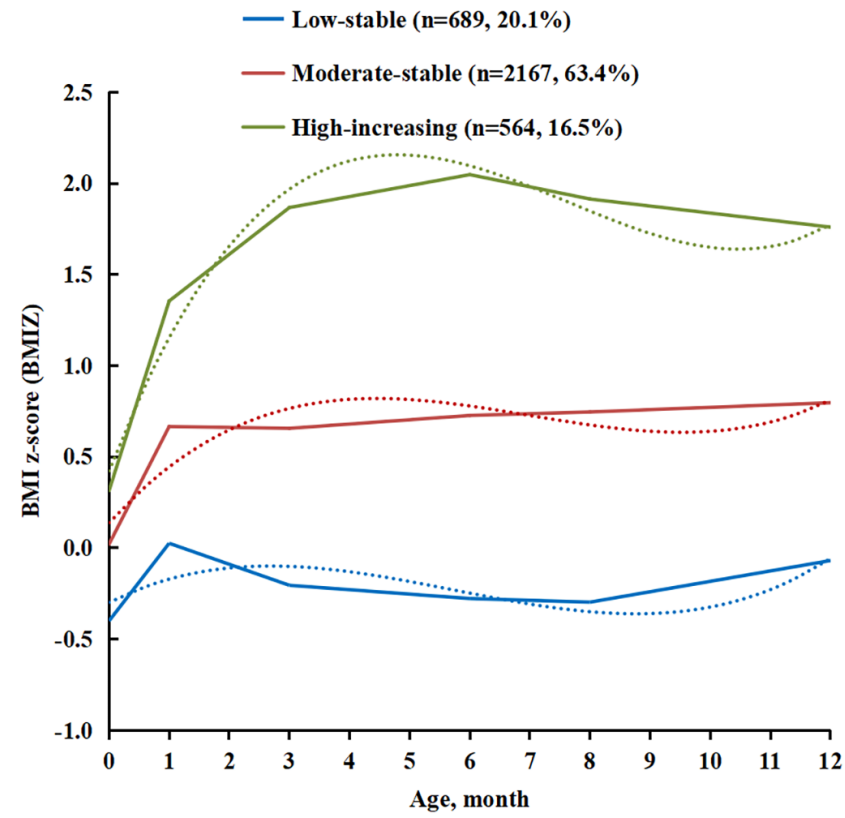

Figure 3 Trajectories in BMI-for-age z-score among 3420 infants (solid line for measuring and dotted line for modelling). BMI, body mass index.

\section{DISCUSSION}

In this study, we revealed heterogeneous trajectories in the physical growth of term-birth infants during the first year after birth by using GBTM. We identified three distinct length, weight and BMI trajectories with characterised features as low-stable, moderate-stable and highincreasing growth. Early-term birth was related to low length/weight growth trajectory.

In our study, early-term infants were more likely to maintain 'low-stable' growth trajectories in length and weight, but less likely to have 'high-increasing' growth trajectories in length. This finding is worth noting even if the physical status of early-term infants was not statistically different from those of the full-term infants at some follow-up time point ( $\geq 8$ months old in length and $\geq 3$ months old in weight, respectively). For some later follow-up time point, there were no statistical differences in length or weight between early-term and full-term infants. The WHO Multicentre Growth Reference Study had confirmed that many living environment factors will affect the physical growth of children. ${ }^{31}$ So it might be that other factors unobserved in this study such as illness, sleep and outdoor activities covered up the influence of gestational age on physical growth at a single time point. We also found that except for its BMI at birth, early-term infants were no longer lower than full-term infants, and even higher at some time points like months 6 and 8 (table 2). We thought this was because early-term infants' weight gain rate was higher than its length growth rate.

Few studies focused on early-term infants at length or weight trajectory. A study of SGA infants showed that early-term SGA infants' height trajectory SD scores and the catch-up rate for height maintained lower level up to 
Table 3 OR $(95 \% \mathrm{Cl})$ of the association of different term infants with LAZ, WAZ and BMIZ trajectories

\begin{tabular}{|c|c|c|c|c|}
\hline \multirow[b]{2}{*}{ Types of gestational age } & \multicolumn{2}{|l|}{ Low stable } & \multicolumn{2}{|l|}{ High increasing } \\
\hline & Crude & Adjusted & Crude & Adjusted \\
\hline \multicolumn{5}{|l|}{ LAZ } \\
\hline Full-term & 1.00 (reference) & 1.00 (reference) & 1.00 (reference) & 1.00 (reference) \\
\hline \multicolumn{5}{|l|}{ WAZ } \\
\hline Full-term & 1.00 (reference) & 1.00 (reference) & 1.00 (reference) & 1.00 (reference) \\
\hline \multicolumn{5}{|l|}{$\mathrm{BMIZ}^{\dagger}$} \\
\hline Early-term & 1.07 (0.89 to 1.29$)$ & 0.91 (0.48 to 1.73$)$ & 1.03 (0.84 to 1.26$)$ & 1.02 (0.53 to 1.97$)$ \\
\hline Full-term & 1.00 (reference) & 1.00 (reference) & 1.00 (reference) & 1.00 (reference) \\
\hline
\end{tabular}

*Adjusted for maternal age at delivery, maternal height, maternal weight before pregnancy, paternal height, paternal weight, maternal smoking, drinking, complications during pregnancy, infant sex, whether infant was mother's firstborn, caesarean section, and neonatal complications.

†Adjusted for maternal age at delivery, maternal pre-pregnancy overweight/obsity, weight gain during pregnancy, maternal smoking, drinking, complications during pregnancy, infant sex, whether infant was mother's firstborn, caesarean section, and neonatal complications.

BMI, body mass index; BMIZ, BMI-for-age z-score; LAZ, length-for-age z-score; WAZ, weight-for-age z-score.

18 months old in comparison with full-term SGA infants; a finding that was similar with our results. ${ }^{19}$ More studies focused on children's BMI trajectory. A study to identify BMI trajectories from birth to 10 years old reported that gestational age was lower in the lower percentile BMI trajectories. ${ }^{32}$ However, the generalisation of these studies was limited by the assumption that the study population was homogeneous. Other studies using GBTM (followed up to 8 and 12 years old, respectively) suggested no difference in gestational age among BMI trajectories. ${ }^{334}$ These findings were possibly due to that the longer follow-up years had concealed the impact produced by different gestational ages, which reminds us to explore the duration of the low trajectories in childhood. As for this study, we examined the influence of gestational age on BMI trajectory during infancy and observed no statistical association between them.

Furthermore, the low weight growth trajectories or low weight gain in infancy had been reported to be associated with adverse health outcomes. A birth cohort study reported that poor bone mineralisation at 7 years old was related to lower weight trajectory. ${ }^{35}$ Another study that included 5390 term infants found that lower weight gain in infancy was associated with poor adult (31 years old) lung function. ${ }^{36}$ Moreover, early-term infants included in this study showed a high risk of neonatal complications

Table 4 Adjusted ORs for different growth trajectories stratifying by infant sex

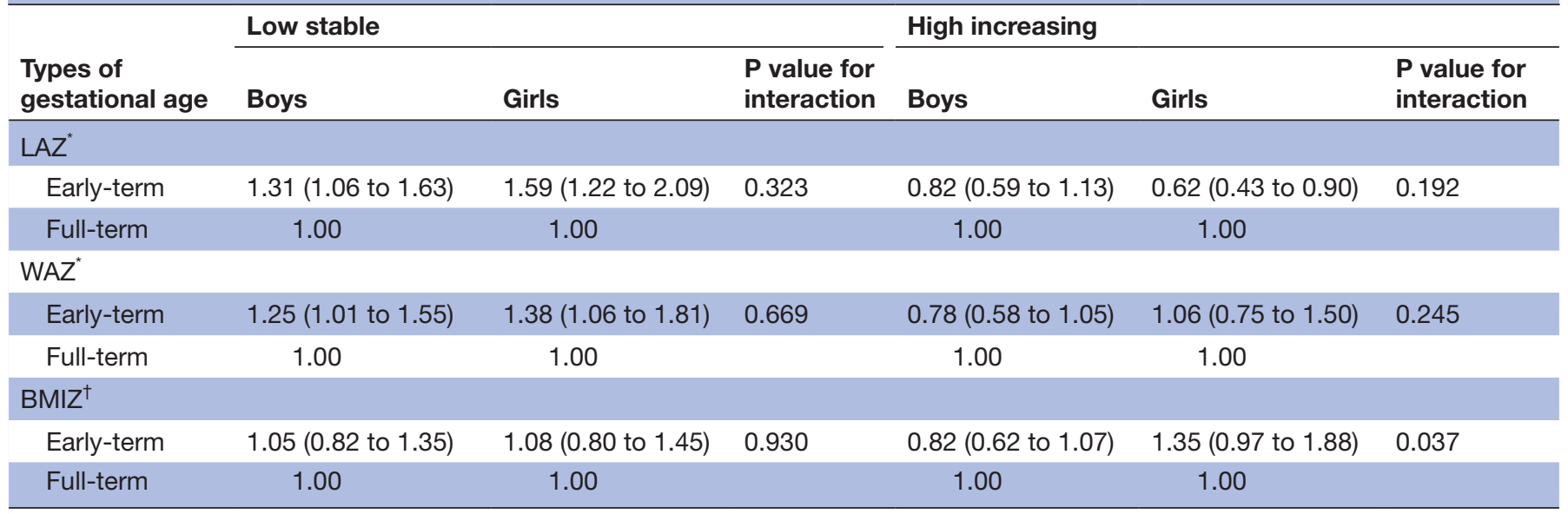

*Adjusted for maternal age at delivery, maternal height, maternal weight before pregnancy, paternal height, paternal weight, maternal smoking, drinking, complications during pregnancy, whether infant was mother's firstborn, caesarean section, and neonatal complications.

†Adjusted for maternal age at delivery, maternal pre-pregnancy overweight/obsity, weight gain during pregnancy, maternal smoking, drinking, complications during pregnancy, whether infant was mother's firstborn, caesarean section, and neonatal complications. BMI, body mass index; BMIZ, BMI-for-age z-score; LAZ, length-for-age z-score; WAZ, weight-for-age z-score. 
like in previous studies. ${ }^{3-6} 3738$ Further research is necessary to discuss whether early-term infants' early childhood length/weight trajectory plays an intermediary role between neonatal complications and childhood adverse health outcomes.

There were several notable limitations in our study. First, there may be selection bias because of the nonpopulation-based study. Second, although our results were robust after controlling extensive potential confounders, residual confounding could not be eliminated completely for some variables not covered in this study, such as different growth environment factors, feeding and lifestyle of individuals. Third, our study only obtained follow-up data during infancy. We would need further research to explore how long the different growth trajectories in early childhood persist and determine whether the differences would affect health in later childhood and even adulthood.

\section{Conclusion}

In this study, we identified three distinct trajectories characterised as low stable, moderate stable, and high increasing in length, weight, and BMI by using GBTM. Our study found the association of early-term birth and low length/weight rather than BMI trajectory during infancy, which provided evidence for avoiding nonmedically indicated early-term deliveries. Further studies are needed to demonstrate the duration of the trends and their possible long-term health effect.

Correction notice This article has been corrected since it first published. Author 'Rong Yang' affiliation has been updated.

Contributors $\mathrm{KC}$ conceptualised and designed the study, carried out the initial analyses, drafted the initial manuscript, and reviewed and revised the manuscript. $\mathrm{LS}, \mathrm{BL}, \mathrm{YL}$ and MW carried out the initial analyses and reviewed and revised the manuscript. LW, JB and QL collected data and reviewed and revised the manuscript. $\mathrm{YZ}$ and ZT coordinated and supervised data collection. YW conceptualised and designed the study and critically reviewed the manuscript for important intellectual content. RY conceptualised and designed the study, coordinated and supervised data collection, and critically reviewed the manuscript for important intellectual content. RY was responsible for the overall content as the guarantor.

Funding Grants from the Natural Science Fund of Hubei Province, China (\#2018CFC855).

Competing interests None declared.

Patient consent for publication Not required.

Ethics approval This research protocol involves human participants and was approved by the ethics committee of Wuhan Children's Hospital (2020R049-E01). Participants gave informed consent to participate in the study before taking part.

Provenance and peer review Not commissioned; externally peer reviewed.

Data availability statement Data are available upon reasonable request. Data are available on reasonable request by contacting corresponding author (Rong Yang, 442748767@qq.com).

Supplemental material This content has been supplied by the author(s). It has not been vetted by BMJ Publishing Group Limited (BMJ) and may not have been peer-reviewed. Any opinions or recommendations discussed are solely those of the author(s) and are not endorsed by BMJ. BMJ disclaims all liability and responsibility arising from any reliance placed on the content. Where the content includes any translated material, BMJ does not warrant the accuracy and reliability of the translations (including but not limited to local regulations, clinical guidelines, terminology, drug names and drug dosages), and is not responsible for any error and/or omissions arising from translation and adaptation or otherwise.
Open access This is an open access article distributed in accordance with the Creative Commons Attribution Non Commercial (CC BY-NC 4.0) license, which permits others to distribute, remix, adapt, build upon this work non-commercially, and license their derivative works on different terms, provided the original work is properly cited, appropriate credit is given, any changes made indicated, and the use is non-commercial. See: http://creativecommons.org/licenses/by-nc/4.0/.

\section{ORCID iDs}

Kai Chen http://orcid.org/0000-0002-0560-8061

Youjie Wang http://orcid.org/0000-0001-7031-2972

\section{REFERENCES}

1 Fleischman AR, Oinuma M, Clark SL. Rethinking the definition of "term pregnancy". Obstet Gynecol 2010;116:136-9.

2 Stewart DL, Barfield WD, Cummings JJ, et al. Updates on an at-risk population: late-preterm and early-term infants. Pediatrics 2019;144.

3 Sengupta S, Carrion V, Shelton J, et al. Adverse neonatal outcomes associated with early-term birth. JAMA Pediatr 2013;167:1053-9.

4 Seikku L, Gissler M, Andersson S, et al. Asphyxia, neurologic morbidity, and perinatal mortality in early-term and postterm birth. Pediatrics 2016;137.

5 Brown HK, Speechley KN, Macnab J, et al. Neonatal morbidity associated with late preterm and early term birth: the roles of gestational age and biological determinants of preterm birth. Int $J$ Epidemiol 2014;43:802-14.

6 Ghartey K, Coletta J, Lizarraga L, et al. Neonatal respiratory morbidity in the early term delivery. Am J Obstet Gynecol 2012;207:291-2.

7 Kotecha SJ, Gallacher DJ, Kotecha S. The respiratory consequences of early-term birth and delivery by caesarean sections. Paediatr Respir Rev 2016;19:49-55.

8 Schonhaut L, Armijo I, Pérez M. Gestational age and developmental risk in moderately and late preterm and early term infants. Pediatrics 2015;135:e835-41.

9 Edwards MO, Kotecha SJ, Lowe J, et al. Early-term birth is a risk factor for wheezing in childhood: a cross-sectional population study. J Allergy Clin Immunol 2015;136:581-7.

10 Harju M, Keski-Nisula L, Georgiadis L, et al. The burden of childhood asthma and late preterm and early term births. $J$ Pediatr 2014;164:295-9.

11 Beauregard JL, Drews-Botsch C, Sales JM, et al. Preterm birth, poverty, and cognitive development. Pediatrics 2018;141:1. doi:10.1542/peds.2017-0509

12 Quigley MA, Poulsen G, Boyle E, et al. Early term and late preterm birth are associated with poorer school performance at age 5 years: a cohort study. Arch Dis Child Fetal Neonatal Ed 2012;97:F167-73.

13 Chan E, Quigley MA. School performance at age 7 years in late preterm and early term birth: a cohort study. Arch Dis Child Fetal Neonatal Ed 2014;99:F451-7.

14 Lindström K, Lindblad F, Hjern A. Preterm birth and attention-deficit/ hyperactivity disorder in schoolchildren. Pediatrics 2011;127:858-65.

15 Sucksdorff M, Lehtonen L, Chudal R, et al. Preterm birth and poor fetal growth as risk factors of Attention-Deficit/ hyperactivity disorder. Pediatrics 2015;136:e599-608.

16 Martin JA, Hamilton BE, Sutton PD. Births: final data for 2009. Natl Vital Stat Rep 2010;59:1-70.

17 Boyle EM, Poulsen G, Field DJ, et al. Effects of gestational age at birth on health outcomes at 3 and 5 years of age: population based cohort study. BMJ 2012;344:e896.

18 Helle E, Andersson S, Häkkinen U, et al. Morbidity and health care costs after early term birth. Paediatr Perinat Epidemiol 2016;30:533-40.

19 Maeyama K, Morioka I, Iwatani S, et al. Gestational age-dependency of height and body mass index trajectories during the first 3 years in Japanese small-for-gestational age children. Sci Rep 2016;6:38659.

20 Nagin DS. Group-based trajectory modeling: an overview. Ann Nutr Metab 2014;65:205-10.

21 Kwon S, Janz KF, Letuchy EM, et al. Association between body mass index percentile trajectories in infancy and adiposity in childhood and early adulthood. Obesity 2017;25:166-71.

22 Giles LC, Whitrow MJ, Davies MJ, et al. Growth trajectories in early childhood, their relationship with antenatal and postnatal factors, and development of obesity by age 9 years: results from an Australian birth cohort study. Int J Obes 2015;39:1049-56.

23 Yang R, Liang S, Flick LH, et al. Relationship between common mental disorder symptoms during pregnancy and preterm birth among Chinese women in Wuhan. Matern Child Health $J$ 2016;20:2121-9. 
24 Jones BL, Nagin DS, Roeder K. A SAS procedure based on mixture models for estimating developmental trajectories. Sociol Methods Res 2001;29:374-93. doi:10.1177/0049124101029003005

25 Nagin DS, Odgers CL. Group-based trajectory modeling in clinical research. Annu Rev Clin Psychol 2010;6:109-38.

26 Suzuki K, Sato M, Zheng W, et al. Childhood growth trajectories according to combinations of pregestational weight status and maternal smoking during pregnancy: a multilevel analysis. PLOS One 2015;10:e118538.

27 Polidori N, Castorani V, Mohn A, et al. Deciphering short stature in children. Ann Pediatr Endocrinol Metab 2020;25:69-79.

28 Haga C, Kondo N, Suzuki K, et al. Developmental trajectories of body mass index among Japanese children and impact of maternal factors during pregnancy. PLOS One 2012;7:e51896.

29 Jaddoe VWV, de Jonge LL, Hofman A, et al. First trimester fetal growth restriction and cardiovascular risk factors in school age children: population based cohort study. BMJ 2014;348:g14.

30 Kernan WN, Viscoli CM, Brass LM, et al. Phenylpropanolamine and the risk of hemorrhagic stroke. N Engl J Med 2000;343:1826-32.

31 de Onis M, Garza C, Victora CG, et al. The WHO multicentre growth reference study: planning, study design, and methodology. Food Nutr Bull 2004;25:S15-26.
32 Péneau S, Giudici KV, Gusto G, et al. Growth trajectories of body mass index during childhood: associated factors and health outcome at adulthood. J Pediatr 2017;186:64-71.

33 Pryor LE, Tremblay RE, Boivin M, et al. Developmental trajectories of body mass index in early childhood and their risk factors: an 8-year longitudinal study. Arch Pediatr Adolesc Med 2011;165:906-12.

34 Li C, Goran MI, Kaur H, et al. Developmental trajectories of overweight during childhood: role of early life factors. Obesity 2007:15:760-71.

35 Monjardino T, Rodrigues T, Inskip H, et al. Weight trajectories from birth and bone mineralization at 7 years of age. $J$ Pediatr 2017;191:117-24.

36 Canoy D, Pekkanen J, Elliott P, et al. Early growth and adult respiratory function in men and women followed from the fetal period to adulthood. Thorax 2007;62:396-402.

37 Jensen JR, White WM, Coddington CC. Maternal and neonatal complications of elective early-term deliveries. Mayo Clin Proc 2013;88:1312-7.

38 Parikh LI, Reddy UM, Männistö T, et al. Neonatal outcomes in early term birth. Am J Obstet Gynecol 2014;211:265.e1-e11. doi:10.1016/j.ajog.2014.03.021 